\title{
Morphometry and Morphology of Rouviere's Sulcus of Liver for Laparoscopic Cholecystectomy - A Cadaveric Study
}

\author{
Deepali D. Deshatty ${ }^{1}$, Shruthi B.N. ${ }^{2}$, Kavitha S33, Merlyn Madhumitha L. ${ }^{4}$ \\ 1,2,3,4 Department of Anatomy, Rajarajeswari Medical College \& Hospital, Bangalore, Karnataka, India.
}

\section{ABSTRACT}

\section{BACKGROUND}

The Rouviere's sulcus (RS) is a horizontal sulcus on inferior surface of liver. The identification of RS may avoid bile duct injury during laparoscopic cholecystectomy and reduce the number of complications. RS is useful but often ignored anatomic landmark. The purpose of the study was to determine the presence/absence, types, and morphometry of demonstrable Rouviere's sulcus.

\section{METHODS}

This observational study was conducted on 50 (cadaveric) liver specimens obtained during dissection. All the surfaces were meticulously observed, the RS was identified and photographed. The parameters like its presence/ absence, type of sulcus, length, breadth and depth were measured. Later it is classified into type 1, 2 \& 3 depending on its morphology.

\section{RESULTS}

The Rouviere's sulcus was present in 36 (72 \%) specimens. The type 1RS in 29 (58 $\%)$, type 2 RS in 4 (8\%) and type 3 RS in 3 (6\%) specimens was observed. The RS was horizontal in $25(50 \%)$ specimens and oblique in $11(22 \%)$ specimens. The average length, breadth and depth of RS were $3.5 \mathrm{~cm}, 0.14 \mathrm{~cm} \& 0.52 \mathrm{~cm}$ respectively.

\section{CONCLUSIONS}

The knowledge of presence / absence of Rouviere's sulcus, its type and morphometry provide useful information to the surgeons to avoid bile duct injury during laparoscopic cholecystectomy and to achieve a good outcome.

\section{KEY Words}

Rouviere's Sulcus, Laparoscopic Cholecystectomy, Bile Duct Injury
Corresponding Author:

Dr. Shruthi BN,

Professor \& HOD,

Rajarajeshwari Medical College \&

Hospital, Bangalore,

Karnataka, India.

E-mail:drshruthilon@gmail.com

DOI: $10.14260 / j e m d s / 2021 / 296$

How to Cite This Article:

Deshatty DD, Shruthi BN, Kavitha S, et al. Morphometry and morphology of Rouviere's sulcus of liver for laparoscopic cholecystectomy - a cadaveric study. J Evolution Med Dent Sci 2021;10(19):14031407, DOI: 10.14260/jemds/2021/296

Submission 26-11-2020, Peer Review 09-03-2021, Acceptance 16-03-2021, Published 10-05-2021.

Copyright (c) 2021 Deepali D. Deshatty et al. This is an open access article distributed under Creative Commons Attribution License [Attribution 4.0 International (CC BY 4.0)] 


\section{BACKGROUND}

Rouviere's Sulcus (RS) is also known as Incisura hepatica dextra or Gans incisura. ${ }^{1}$ The sulcus is named after Henri Rouviere, a French anatomist, who had initially identified and described it. ${ }^{2}$ The RS, which is present in most livers, finds its significance in serving as a prominent landmark for a safe laparoscopic cholecystectomy. The RS serves as an extra biliary reference point exclusively in laparoscopic cholecystectomy, because of the creation of pneumoperitoneum wherein carbon dioxide is commonly used for insufflation. This inflation leads to increased prominence and hence easy identification of the RS. ${ }^{3}$

Laparoscopic cholecystectomy involves the removal of the gall bladder most commonly due to the presence of gallstones. It is a less invasive method when compared to surgical cholecystectomy and hence ensures a shorter hospital stay, shorter recovery period and involves less pain to the patient.

Some common complications during a laparoscopic cholecystectomy include bleeding, infection to the viscera, and injury to the bile duct and major blood vessels. The occurrence of bile duct injuries during laparoscopic cholecystectomy is around $0.5 \%$, despite much advancement in the procedure, there has been no decline in this rate ${ }^{4-7}$. Thorough knowledge of hepatobiliary anatomy is a must for the surgeon to avoid such serious complications. The identification of anatomical structures in laparoscopic surgery is slightly complex as the structures exist in a three-dimensional plane but the surgeon's view of the same is only two-dimensional. Infection, inflammation during acute cholecystitis, unclear or distorted anatomy and haemorrhage are some other factors that may lead to an injury during laparoscopic cholecystectomy. ${ }^{5,8}$

The Rouviere's sulcus is usually seen on the right lobe of the liver extending from fissure on the liver between the right lobe and the caudate process, measuring $2-3 \mathrm{~cm}$ and containing the right portal triad or its branches. This sulcus can be used to accurately identify the plane of the common bile duct. Hence injury to the bile duct can be avoided during laparoscopic cholecystectomy by identifying RS. As the Rouviere's sulcus has not been extensively analysed upon and there is no record of this sulcus in anatomical or surgical literature except for a few recently published articles or journals this study focuses on identifying the Rouviere's sulcus.

Therefore, this study intends to determine: 1) presence / absence of RS 2) It's morphometry 3) different types of RS.

\section{METHODS}

The observational study was done on 50 liver specimens obtained from $10 \%$ formalin-fixed cadavers in the Department of Anatomy, Rajarajeswari Medical College and Hospital, Bangalore. The duration of the study was from October 2018 to August 2020. Adult cadavers both male and female, between the age group of 20 - 60 years were included and the specimens with hepatic pathologies, livers subjected to surgery and abdominal trauma were excluded.

Each liver was thoroughly examined and the presence/absence of the sulcus was observed and noted. The sulcus if present was identified and classified as type 1 (A or
B), 2 or 3 following the terminology and classification system proposed by Singh and Prasad $^{3}$ and Lazarus et al. ${ }^{9}$ The direction of orientation of the sulcus was observed and recorded. The length of the sulcus was measured using a nylon thread and extrapolating it on a measuring tape. The breadth of the sulcus was measured using a measuring tape. The depth of open type of sulcus was measured using a steel scale at maximum depth. The collected data was tabulated and statistically analysed.

\section{Statistical Analysis}

Mean, standard deviation and percentage were calculated using SPSS Windows Software

\section{RESULTS}

Out of 50 dissected livers, the Rouviere's sulcus (RS) was present in 36 (72\%) specimens and absent in 14 (28\%) specimens.

\section{Types of RS (Table 1)}

We classified RS into type 1, type 2 and type 3 based on degree of depth of sulcus into the liver tissue of the right lobe.3,9 The Type 1 was defined as a deep sulcus which was observed in 29 specimens (58\%) and it was again divided as type $1 \mathrm{~A}$ and type 1B. The type $1 \mathrm{~A}$ sulcus was open at its medial end and continuous with porta hepatis, and was found in 24 specimens (48\%). Type $1 \mathrm{~B}$ when sulcus is closed at medial end, was found in 5 specimens (10\%). The Type 2 RS was described as slit like narrow sulcus and was seen in 4 specimens ( $8 \%)$. The Type 3 RS was described as scar-like white line where parenchyma appeared to have fused and was observed in 3 specimens (6\%).

\section{Direction of RS (Table 1)}

The direction of RS observed. It was horizontal in 25 specimens (50\%) and oblique in 11 specimens (22\%).

\begin{tabular}{|c|c|c|}
\hline \multicolumn{3}{|c|}{ Number and Percentage of Specimen Showing Different Types of RS } \\
\hline Types of RS & Number of Specimens & Percentage (\%) \\
\hline 1 & 29 & 58 \\
\hline 2 & 4 & 8 \\
\hline 3 & 3 & 6 \\
\hline Absence of RS & 14 & 28 \\
\hline Total & 50 & 100 \\
\hline \multicolumn{3}{|c|}{$\begin{array}{l}\text { Number and Percentage of Specimen Showing Different Direction of } \\
\text { RS }\end{array}$} \\
\hline Direction of RS & Number of Specimens & Percentage (\%) \\
\hline Horizontal & 25 & 50 \\
\hline Oblique & 11 & 22 \\
\hline Vertical & 0 & 0 \\
\hline Absence of RS & 14 & 28 \\
\hline Total & 50 & 100 \\
\hline
\end{tabular}

\section{Morphometry of RS (Table 2)}

The length, breadth and depth of RS in each specimen were measured. The average length of RS was $3.5 \mathrm{~cm}$ with standard deviation $1.08 \mathrm{~cm}$. The average breadth of RS was $0.14 \mathrm{~cm}$ with 
standard deviation $0.11 \mathrm{~cm}$. The average depth of RS was 0.52 $\mathrm{cm}$ with standard deviation $0.39 \mathrm{~cm}$.

\begin{tabular}{|ccccc|}
\hline Parameter & $\begin{array}{c}\text { Maximum } \\
(\mathbf{c m})\end{array}$ & $\begin{array}{c}\text { Minimum } \\
\text { (cm) }\end{array}$ & $\begin{array}{c}\text { Average } \\
(\mathbf{c m})\end{array}$ & $\begin{array}{c}\text { Standard } \\
\text { Deviation }\end{array}$ \\
Length & 5.2 & 1.5 & 3.5 & 1.08 \\
Breadth & 0.5 & 0.1 & 0.14 & 0.11 \\
Depth & 1 & 0.1 & 0.52 & 0.39 \\
\hline \multicolumn{4}{r}{ Table 2. Morphometry of RS in the Present Study } \\
\hline
\end{tabular}

\section{DISCUSSION}

The Rouviere's sulcus is not found in standard anatomy textbooks ${ }^{10,11}$ but is mentioned in various surgical and anatomical literatures. Various authors had given different names until Rouviere named it.12,13,14,15 This sulcus originally described by Rouviere in 1924 as 'sillon du processus caude' can be translated as grooves or furrows of the caudate lobe of liver, details of the groove were described. It was more commonly seen in livers of foetuses and newborns (81\%) compared to livers of adults ( $52 \%$ ), thus groove becomes less noticeable with advancing age. ${ }^{2}$ The sulcus named as incisura dextra' by Henry Gans in 1955, ${ }^{1}$ then Couinad described it as 'le sillon du processus caude de Rouviere',14 later Reynold et al. called it as 'incisura dextra of Gans' in $1991 .^{12}$ Then a later all the literature mentioned it as Rouviere's sulcus.

As the RS corresponds to the level of the porta hepatis where the right pedicle enters the liver, the plane of bile duct is indicated accurately. Cholecystectomy is the major surgery which gets affected by the advent of laparoscopy as gallbladder surgery, i.e., cholecystectomy. ${ }^{16}$ Identification of RS and keeping the dissection ventral to it is one of the successful methods to prevent the bile duct injury. ${ }^{15}$ Although recently its significance in laparoscopic cholecystectomy has been appreciated, there are nearly no clinical trials specifying the outcome of surgery in terms of bile duct injury.

The works of various authors on morphology and morphometry of RS is compared and tabulated.3,9,17,18 (Table 3 and 4).

\section{Morphology of RS (Table 3)}

In a study by Singh et al. have found out different forms of RS and have labelled as scar (if the sulcus was seen only as a white scar near porta hepatis), slit (if it was a shallow and narrow sulcus) and deep sulcus. They have further categorised the deep sulcus into open and closed type. In the present study, the Rouviere's sulcus was classified into type 1, type 2 and type 3 . The type $1 \mathrm{RS}$ is deep sulcus which is most common, it can be seen open at medial end, continuous with portal hepatis (type $1 \mathrm{~A}$ ) or it can be closed at the medial and lateral end (type 1B). This deep sulcus is reported as fully open, partially open, throughout its length open, cleft with or without visualisation of hepatic pedicle. ${ }^{15,18}$ The type 2 RS is slit and is described as small, superficial, narrow. Rouviere described it as 'a fine groove on inferior surface'. The type 3 RS represents fused sulcus, which appears like white line, also mentioned as scar.

In our study RS was observed in $72 \%$ specimens comparable to observation noted by other authors. Singh and Prasad $^{3}$ reported $100 \%$ presence of RS as their study sample was recordings of laparoscopic cholecystectomy in which RS was visibly present. Type 1 RS was the most common type reported by various authors including present study. Type 1 RS was found in $58 \%$ specimens which was comparable to $\mathrm{AL}$ Naser et al. ${ }^{16}$ \& Lazarus et al. Type 2 RS was not observed by Dahmne et al. ${ }^{18}$ \& Type 3 RS was not observed by AL-Naser et al. ${ }^{17}$. Singh and Prasad ${ }^{3}$ found RS was vertical in $2 \%$ cases, which was not found in present study. The RS was directed horizontal and oblique in equal specimens (41.33\%) in study done by Lazarus et al. ${ }^{9}$ The RS was directed oblique in $97 \%$ cases in Damhne et al. ${ }^{18}$ study. The commonest direction of sulcus is horizontal, less commonly oblique and very rarely vertical.

\begin{tabular}{|c|c|c|c|c|c|c|c|}
\hline \multirow{2}{*}{$\begin{array}{c}\text { Author } \\
\text { (year) }\end{array}$} & \multirow{2}{*}{$\begin{array}{c}\text { Sample } \\
\text { Size }\end{array}$} & \multicolumn{3}{|c|}{ Types of RS (\%) } & \multicolumn{3}{|c|}{ Direction of RS (\%) } \\
\hline & & Type 1 & Type 2 & Type 3 & Horizont & Oblique & Vertical \\
\hline $\begin{array}{l}\text { Dahmane et } \\
\text { al. (2013) }\end{array}$ & 40 & 70 & 0 & 12 & 3 & 97 & 0 \\
\hline $\begin{array}{l}\text { Singh and } \\
\text { Prasad } \\
\text { (2017) }\end{array}$ & 100 & 71 & 23 & 6 & 70 & 31 & 2 \\
\hline $\begin{array}{l}\text { Al-Nazer } \\
(2018)\end{array}$ & 402 & 54.9 & 24.4 & 0 & - & - & - \\
\hline $\begin{array}{l}\text { Lazarus et } \\
\text { al. (2018) }\end{array}$ & 75 & 50.67 & 25.33 & 6.67 & 41.33 & 41.33 & 0 \\
\hline $\begin{array}{c}\text { Present } \\
\text { study } \\
(2020) \\
\end{array}$ & 50 & 58 & 8 & 6 & 50 & 22 & 0 \\
\hline Table 3 & vpes & Dir & onc & $\mathrm{Cor}$ & ed wi & ior & hors \\
\hline
\end{tabular}

\section{Morphometry of RS (Table 4)}

The Rouviere described in his original studies that this sulcus was present over 'one third of the total width of the right lobe of liver' without giving any measurement. ${ }^{2}$ Only few previous studies have measured the RS. The mean length and mean breadth noted in present study are comparable to findings of Lazarus et al. The maximum mean breadth $(1.11 \mathrm{~cm})$ and maximum mean depth $(1.11 \mathrm{~cm})$ noted by Singh and Prasad ${ }^{3}$, it could be because the study was undertaken to record 100 videos laparoscopic cholecystectomy procedures, in which Rouviere's sulcus was seen. The maximum mean length (3.5 $\mathrm{cm}$ ) was noted in present study.

\begin{tabular}{|ccccccccc|}
\hline $\begin{array}{c}\text { Author } \\
\text { (year) }\end{array}$ & $\begin{array}{c}\text { Method of } \\
\text { Study }\end{array}$ & $\begin{array}{c}\text { Sample } \\
\text { Size }\end{array}$ & $\begin{array}{c}\text { Length } \\
\text { (cm) } \\
\text { Mean }\end{array}$ & $\begin{array}{c}\text { Breadth } \\
\text { (cm) }\end{array}$ & $\begin{array}{c}\text { Depth } \\
\text { (cm) }\end{array}$ \\
$\begin{array}{c}\text { Dahmane et al. } \\
(2013)\end{array}$ & Cadaveric & 40 & 2.8 & 0.4 &. & & 0.6 & 0.2 \\
$\begin{array}{c}\text { Singh and } \\
\text { Prasad (2017) } \\
\begin{array}{c}\text { Lazarus et al. } \\
(2018)\end{array}\end{array}$ & $\begin{array}{c}\text { Recordings of } \\
\text { laparoscopic } \\
\text { cholecystectomy }\end{array}$ & 100 & 2.31 & 0.3 & 1.11 & 0.2 & 1.11 & 0.2 \\
$\begin{array}{c}\text { Present study } \\
(2020)\end{array}$ & Cadaveric & 75 & 3.16 &.. & 0.16 & & 0.78 & \\
\hline Table 4. Morphometry of RS Compared with Various Authors & \\
\hline
\end{tabular}

\section{Surgical Importance}

The minimal common bile duct injury during laparoscopic cholecystectomy is shown by beginning of dissection ventral to RS. ${ }^{19}$ The RS can be identified in $80 \%$ cases and determines plane of common bile duct accurately. It is taken as starting reference point for safe dissection. ${ }^{20}$ It is lesser known but important constant anatomic landmark on liver surface, which is not distorted by any pathology, and can be used to prevent bile duct injury during laparoscopic cholecystectomies, an additional strategy along with Calot's triangle to achieve 
critical view of safety. ${ }^{21,22,23}$ Identification of RS during laparoscopic cholecystectomy strengthens surgeon's confidence and also helps in reducing the operative time with safety especially during surgeon's learning curve of laparoscopy, then only one could reach to zero bile duct injury level in surgery. ${ }^{24}$

As the RS is not easily seen in the cadaver, most of the anatomy books do not mention about it. We have made an attempt to give comprehensive details about the morphology and morphometry of RS. Rouviere in his original study described the sulcus as being present over one third of the total width of the right lobe of the liver without giving any measurements in $\mathrm{cm}$. Only two previous studies have measured the sulcus in $\mathrm{cm}$, and our results compare well with them.

As there is an increased incidence of bile duct injuries with the advent of laparoscopic cholecystectomy, RS has been identified as extra biliary landmark that may mitigate iatrogenic injuries resulting from such hepatobiliary surgeries. This study adds to the thorough understanding of the anatomy of RS. This in turn helps surgeons and hepatologists.

The identification of RS also helps to perform safe right segmental liver resection. The Glisson's capsule of liver, which is a fibrous sheath encircles the bile duct, hepatic artery and portal vein at the hilum and continues as capsule. Segmental resection of liver can be done by Glissonian approach, mainly for segment V, VI and VII with RS as guide, as these segments pedicle bifurcates early near hilar plate and their course may be present inside RS. Damhne et al. reported branches of the right posterior segmental pedicle in RS in $70 \%$ of cases. Hence, elective vascular control during segment-oriented approach to right liver resection can be done by finding / locating RS. ${ }^{18}$ Although pure laparoscopic anatomical segmental resection is difficult to perform, the Kim et al. described the Glissonian approach at Rouviere's sulcus as a landmark along with modified liver hanging manoeuvre which could be safe and useful for laparoscopic anatomical segment VI resection. ${ }^{25}$

\section{CONCLUSIONS}

Rouviere's sulcus is a valuable anatomical landmark and relatively easy to appreciate and represents plane of common bile duct. Hence, accurate knowledge of Rouviere's sulcus is essential to minimize bile duct injury during laparoscopic cholecystectomy. By dissecting ventral to Rouviere's sulcus, the surgeon ensures that they are operating away from the danger area. More emphasis should be given for identification of Rouviere's sulcus, especially for surgeons during their learning curve of laparoscopic cholecystectomy to minimize bile duct injury. Also, Rouviere's sulcus acts as a guide for right segmental liver resection, it's finding and study is valuable for surgeons.

Data sharing statement provided by the authors is available with the full text of this article at jemds.com.

Financial or other competing interests: None.

Disclosure forms provided by the authors are available with the full text of this article at jemds.com.

\section{REFERENCES}

[1] Gans H. Introduction to hepatic surgery. Netherlands: Elsevier 1955:50-3, 220-4.

[2] Rouviere H. On the configuration and the significance of groove of the caudate process. Newsletter and Memoir of the Anatomical Society of Paris 1924;94:355-8.

[3] Singh M, Prasad N. The anatomy of Rouviere's sulcus as seen during laparoscopic cholecystectomy: a proposed classification. J Min Access Surg 2017;13(2):89-95.

[4] Connor S, Garden OJ. Bile duct injury in the era of laparoscopic cholecystectomy. Br J Surg 2006;93(2):15868.

[5] Wu YV, Linehan DC. Bile duct injuries in the era of laparoscopic cholecystectomies. Surg Clin North Am 2010;90(4):787-802.

[6] MacFadyen BV, Vecchio R, Ricardo AE, et al. Bile duct injury after laparoscopic cholecystectomy. Surg Endosc 1998;12(4):315-21.

[7] Slater K, Strong RW, Wall DR, et al. Iatrogenic bile duct injury: the scourge of laparoscopic cholecystectomy. ANZ J Surg 2002;72(2):83-8.

[8] Lockhart S, Singh-Ranger G. Rouviere's sulcus-aspects of incorporating this valuable sign for laparoscopic cholecystectomy. Asian J Surg 2018;41(1):1-3.

[9] Lazarus L, Luckrajh JS, Kinoo SM, et al. Anatomical parameters of the Rouviere's sulcus for laproscopic cholecystectomy. Eur J Anat 2018;22(5):389-95.

[10] Williams PL, Bannister LH, Berry MM, et al. Gray's anatomy: the anatomical basis of medicine and surgery. $38^{\text {th }}$ edn. New York: Churchill Livingstone 1995.

[11] Moore KL, Dalley AF. Clinical Oriented Anatomy. $4^{\text {th }}$ edn. Philadelphia, USA: Lippincott Williams \& Wilkins 1999.

[12] Reynaud BH, Coucoravas GO, Giuly JA. Basis to improve several hepatectomy techniques involving the surgical anatomy of incisura dextra of gans. Surg Gynecol Obstet 1991;172(6):490-2.

[13] Stringer MD. Eponyms in surgery and anatomy of the liver, bile ducts and pancreas. London, UK: Royal Society of Medicine Press 2009.

[14] Couinaud C. Le foie: etudes anatomiques et chirurgicales. Paris, France: Masson 1957.

[15] Hugh TB, Kelly MD, Mekisic A. Rouviere's sulcus: a useful landmark in laparoscopic cholecystectomy. Br J Surg 1997;84(9):1253-4.

[16] Singh M, Jain A, Dey S, et al. Rouviere's sulcus and critical view of safety: a guide to prevent bile duct injury during laparoscopic cholecystectomy. World Journal of Laparoscopic Surgery 2018;11(1):25-8.

[17] Al-Naser MKH. Rouviere's sulcus: a useful anatomical landmark for safe laparoscopic cholecystectomy. Int J Med Res Health Sci 2018;7(1):158-61.

[18] Dahmane R, Morjane A, Starc A. Anatomy and surgical relevance of Rouviere's sulcus. Scientific World Journal 2013;2013:254287.

[19] Hugh TB. New strategies to prevent laparoscopic bile duct injury--surgeons can learn from pilots. Surgery 2002;132(5):826-35.

[20] Shinde J, Pandit S. Innovative approach to a Frozen Calot's triangle during laparoscopic cholecystectomy. Indian J Surg 2015;77(6):554-7. 
[21] Peti N, Moser MAJ. Graphic reminder of Rouviere's sulcus: a useful landmark in cholecystectomy. ANZ J Surg 2012;82(5):367-8.

[22] Honda G, Iwanaga T, Kurata M, et al. The critical view of safety in laparoscopic cholecystectomy is optimized by exposing the inner layer of the subserosal layer. J Hepatobiliary Pancreat Sci 2009;16(4):445-9.

[23] Singh K, Ohri A. Anatomic landmarks: their usefulness in safe laparoscopic cholecystectomy. Surg Endosc 2006;20(11):1754-8.
[24] Bhatia H, Bharati P, Samta, et al. Rouviere's sulcus as a safety landmark in laparoscopic cholecystectomy. Journal of Medical Science and Clinical Research 2019;7(3):4952.

[25] Kim JH, Cho BS, Jang JH. Pure laparoscopic anatomical segment VI resection using the Glissonian approach, Rouviere's sulcus as a landmark and a modified liver hanging maneuver (with video). Langerbecks Arch Surg 2018;403(1):131-5. 